Journal of Engineering and Applied Sciences 5 (3): 229-233, 2010

ISSN: 1816-949X

(C) Medwell Journals, 2010

\title{
Development of Mobile Intelligent Poultry Feed Dispensing System
}

\author{
${ }^{1}$ O.T. Arulogun, ${ }^{2}$ O.M. Olaniyi, ${ }^{1}$ O.A. Oke and ${ }^{1}$ D.O. Fenwa \\ ${ }^{1}$ Department of Computer Science and Engineering, \\ Ladoke Akintola University of Technology, Ogbomoso, Nigeria \\ ${ }^{2}$ Department of Electronics and Electrical Engineering, Bells University of Technology, \\ Ota, Ogun State, Nigeria
}

\begin{abstract}
Feeding in poultry farming in most developing countries like Nigeria is still manually carried out as high level of human involvement is required. This places an exorbitant cost of production on the farmer and reduces the expected return of investment. Besides, human intervention to poultry feeding is limited to fatigue, negligence, unfavorable weather conditions and improper administration of feeds. In this study, we present a microcontroller based poultry feed dispensing system. The mobile intelligent system is capable of moving forward, turn left, right and has the ability to detect and avoid obstruction. The developed model shows how mechanical transmission systems in machine can imbibe human intelligent of poultry attendants with corresponding increases in cost-benefits and high profits yield from a reduced labour force in poultry farming.
\end{abstract}

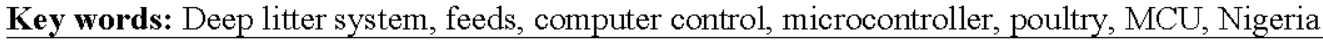

\section{INTRODUCTION}

Poultry farming is a farming system in which birds such as guinea fowls, turkeys, domestic chickens, geese and ducks are raised for the production of meat and eggs. Feathers, hides and skin are other benefits derived from birds such as peacocks and ostriches. According to the World Watch Institute, $74 \%$ of the world's poultry meat and $68 \%$ of eggs are produced this way (Nierenberg, 2006). Poultry industry has become one of the most efficient producers of protein for human consumption. The commercialization of poultry farming in the tropical regions like Nigeria is recent than in the temperate region (Oluyemi and Robelt, 1986; Susan and Anne, 1988; Odunsi, 2009).

Feeding in poultry farming is manually driven in the tropics. This wastes a lot of time and also expends a lot of energy on the human part. The cost of production is highly capital intensive and generation of low profit. Human limitations such as fatigue, stressful manual labour, negligence, unfavorable weather condition in the poultry, poor feeding system, improper administration of feed, inadequate medications and high cost of maintenance are some of the factors that discourage a lot of people's involvement in investing in the poultry industry. These necessitate the need for the emergence of technology that will help to overcome these problems associated with feeding in poultry industry. Also, the problem poultry farmers are facing in caring adequately for their animals is much and in most cases reduce the level of the productivity of their farms. A lot of routine jobs compete for the time of poultry farmers. Among these jobs are feeding of the birds, picking of eggs laid by matured ones and cleaning of their litters among many other things. The duress these farmers undergo increase as the number of their fowls increase (Sainsbury, 2000).

One of the major challenges is having the time sufficient enough to feed these birds their required feeding at fairly regular intervals. However in many instances, feed cannot be simply left in bulk because the animal would either overfeed or eat selectively and allow portions of the feed to spoil. Food costs are important to poultry farmers. According to Odunsi (2009), feed claims about $75 \%$ of the cost of poultry production. Feeding is highly essential as the cost of procurement of the animal itself; thus, the need for its proper management for optimum profit at the end of poultry farming.

To solve the above mentioned problems, feed dispensers have been developed that will discharge feed at specified timed intervals. However, many such feeders are complex, difficult to load or unreliable. The system earlier proposed in Adedinsewo (2004) is dependent on the computer system and cannot detect or avoid obstruction. Also, the proposed system in Omosebi (2006) can only move along the horizontal or vertical axis only depending on its position. These proposed models are

Corresponding Author: O.M. Olaniyi, Department of Electronics and Electrical Engineering, Bells University of Technology, Ota, Ogun State, Nigeria 
dependent on the control program written on computer system and provided control via the parallel port. The computer system's parallel port is affected by cross talk and significant reduction in performance in long distance parallel transmission. Besides, computer process control systems are generally affected by high initial costs and increased dependence on maintenance (Arulogun et al., 2008; Oke et al., 2009).

There is however, a need to develop a system which is independent of the desktop/laptop computer and can also detect and avoid obstructions. The use of a microcontroller as the process controller will eliminates some of the demerits attributed to the personal computercontrolled poultry feed dispenser. The microcontroller is more desirable because of its affordability, reliability, size and low cost (James, 2006). It also has the attribute of a very fast and speedy performance. This single chip gave system designers the capability of developing highly sophisticated applications in one simple component that could be easily embedded into the overall product (Oke et al., 2009).

This study therefore presents a mobile intelligent microcontroller based poultry feed dispensing system capable of combining mobility and human intelligence to the programmability of similar system implementations (Adedinsewo, 2004; Omosebi, 2006) in a deep-litter poultry farming system.

\section{MATERIALS AND METHODS}

System overview: The primary role of a Microcontroller Unit (MCU) in an embedded system is to provide inexpensive, programmable logic control and interfacing to external devices. This means MCU typically is not required to provide highly complex functions. It is well suited to monitoring a selected variety of inputs, including digital signals, button switches and analog inputs and responding to them in real time using the preprogrammed instructions that are executed by the built-in processor. An embedded microcontroller can respond to these inputs with a wide variety of outputs that are appropriate for different devices. These capabilities are available to the designer at a very reasonable cost without a lot of effort.

The overall system is divided into sub-units that are interdependent on one another. The subunits include the controller, the motor and sensor interface circuits, the power supply unit, the sensing unit and the dispenser unit. Figure 1 shows the block diagram of the overall system. The dc source supplies power to all units requiring power while the interface circuit serves as a point of interconnection for the entire system.

\section{Hardware design considerations}

Sensor: The sensor provides an input signal interface for the system against external obstructions. The sensing unit comprises of 3 infrared transmitters and receivers to monitor front, left and right side obstructions. The infrared transmitter radiates optical signal whose reflection by obstructive objects are detected by the receiver. Whenever the reflected rays are received by the receiver, appropriate signals are sent to the microcontroller circuit which produces the necessary control signal that either effect movement of the system in alternative directions or disallow further movement of the system in that direction. Figure 2 shows the circuit diagram of the infrared transmitter designed using 555 timer IC. The timer was configured in monostable multivibrator configuration to generate pulses with a frequency of $40 \mathrm{Khz}$ (Theraja and Theraja, 2002).

The MCU: This basically consists of the PIC16F877A microcontroller. The 16F877A microcontroller is one of the most popular RISC based microcontrollers with 40 pins and it has many internal peripherals and modules. The PIC 16F877A CMOS FLASH-based 8-bit microcontroller is upward compatible with the PIC 16C5x, PIC 12Cxxx and PIC $16 \mathrm{C} 7 \mathrm{x}$ devices. It features 200 ns instruction

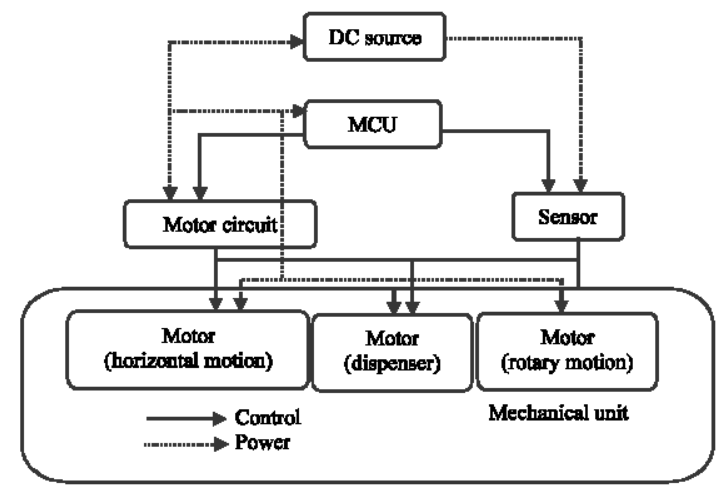

Fig. 1: Overall system block diagram

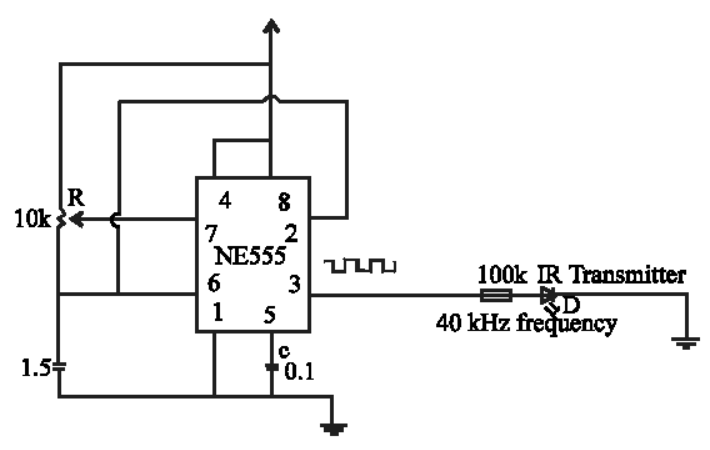

Fig. 2: Infrared transmitter circuit 
execution, 256 bytes of EEPROM data memory, self programming, an ICD, 2 Comparators, 8 channels of 10 -bit Analog-to-Digital (A/D) converter. Some of the external pins of the PIC's I/O port are multiplexed, thus allowing them to perform functions for the peripheral features on the device. Figure 3 shows the control unit of the system.

Mechanical unit: This fabricated unit consists of $3 \mathrm{dc}$ motors, feed dispenser, front and back wheels. The dc motors allow the mechanical sub-system to propel itself and also to dispense appropriate feed. These were achieved when the MCU sends the appropriate signals to them via the motor interface circuit. The choice of using the dc motor was influenced by its properties which include: its fairly constant speed over a wide load range and as the load on the motor increases, so does the armature current and in turn produces a greater torque. One dc motor was connected to the screw conveyor in the dispenser unit whose turning effect causes it to dispense feed at a given rate. The two other motors were used for the mobility of the entire feed dispenser system. The wheel system consists of three wheels like a tricycle, one motor was attached to the two back wheels called the driver which was responsible for the horizontal movement and the other motor was attached to the single

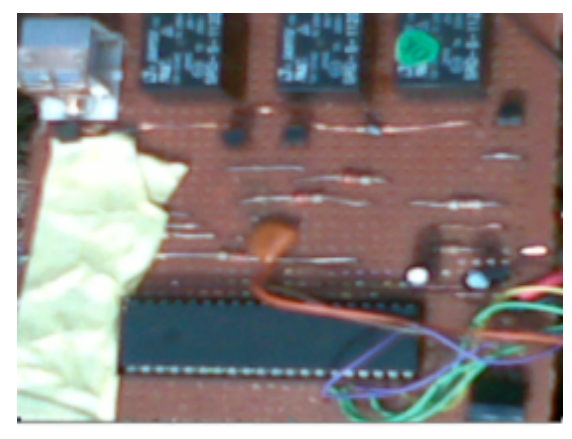

Fig. 3: The PIC 16F877A control unit

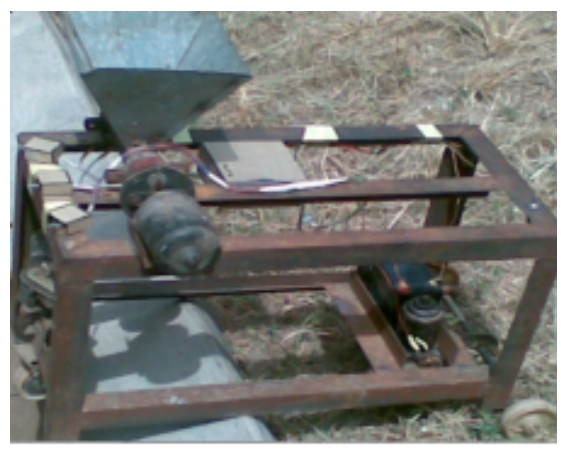

Fig. 4: Mechanical unit front wheel which was responsible for side way movement. Figure 4 shows the picture of the mechanical system that makes up the dispensing unit.

Dc source: Power to the interface control circuit and the motors on the mechanical subsystem of the dispenser were supplied by a $12 \mathrm{~V}$ dc battery for ease of system mobility. The $12 \mathrm{~V}$ dc battery was regulated to $5 \mathrm{~V}$ which was required to power the MCU.

Motor circuit: This consists of the interface circuit that allows the MCU to control the 3 dc motors. The circuit has components passive and active components. The motor interface circuit is shown in Fig. 5 .

Software design considerations: The software was decomposed into modules so that each module could be tested and debugged as an independent unit before final integration as a software system based on the following software design specification. The programming of the PIC was done in assembly language programming for speed optimization. Coding in assembly language represents halfway position between machine code and a high level language. The assembly code is usually a mnemonic derived from the instruction itself i.e., LDA is derived from Load the Accumulator. Assembly code is thus very easy to remember and use when writing programs (Shoewu and Baruwa, 2006). After writing an assembly language program, the programmer must use the assembler specific to the microprocessor or PIC to translate the assembly language into machine code. Assembly language might be used instead of a high-level language for any of 3 major reasons: speed, control and preference. Programs written in assembly usually run faster than those generated by a compiler. Use of assembly language lets a programmer interact directly with the hardware. The software was designed using the following algorithm and was later transformed to PIC assembly language codes.

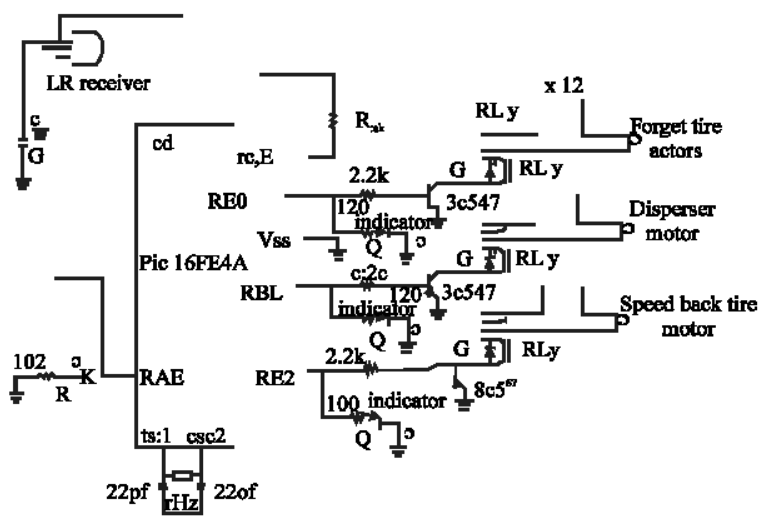

Fig. 5: The de motors control circuit 
Algorithm: The algorithm used to implement the program for the feed dispenser system described in this study is as follows:

Step 1: Power on the system

Step 2: Initialize MCU ports

Step 3: Set the speeds of the dc motors

Step 4: Set the time duration for dispensing of feed

Step 5: If <time duration> is elapsed go to step 14 else go to step 6

Step 6: Energize the dc motors

Step 7: Detect obstructions in the path of the system

Step 8: If No go to step 5 else go to step 14

Step 9: If <obstruction> $>$ FRONT go to step 10, else if $<$ obstruction $>=$ RIGHT go to step 11 else if $<$ obstruction $>=$ LEFT go to step 12 else go to step 12

Step 10: If <time duration> is elapsed go to step 15, else go to step 13

Step 11: Energize the motor for the front wheel to the left (anticlockwise direction) go to step 7

Step 12: Energize the motor for the front wheel to the right (clockwise direction) go to step 7

Step 13: Energize the dc motor for the back wheels in reverse mode. Go to step 7

Step 14: Stop dc motor for the dispensing unit and go to step 9

Step 15: Stop de motor for the dispensing unit return the system to the origin

\section{RESULTS AND DISCUSSION}

The system operation: The $12 \mathrm{~V}$ lead-acid accumulator is used to power the motors and the system associated discrete and active components through the interface circuit. The motor connected to the back tire and the dispenser starts to operate once the battery is switched on. The back tire moves the entire system forward while the dispenser dispenses the feeds on the floor. The indicator connected to each of the motors is used to check if the motors are functioning or not. If the indicator lights up and the front motor do not move then the motor is faulty.

As the machine moves, the infrared transmitter connected to the 555 IC transmits infrared rays continuously. Once the ray hits an obstruction within $10 \mathrm{~cm}$, it reflects back and the rays are being received by the infrared receiver connected to the PIC. The infrared receiver sends a signal to RA0 which then send a signal to RB0 telling the motor controlling the front tire to deflect either towards the left or right depending on which side of the machine the obstruction tends towards. Where the machine could not deflect in either direction, it moves backward. The machine continues to move forward

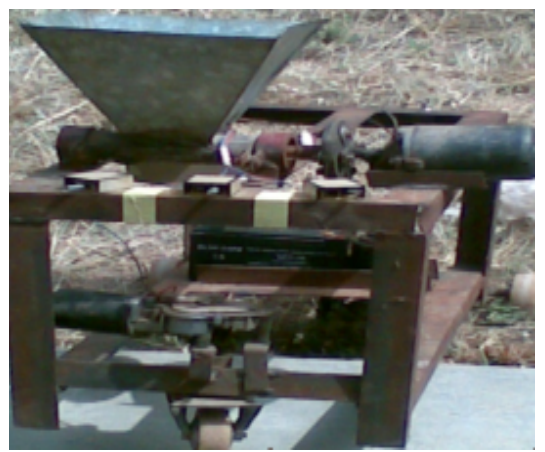

Fig. 6: The developed mobile intelligent feed dispenser

with the dispenser dispensing the feeds until either the battery runs down. The developed system is as shown in Fig. 6.

Testing and evaluation of the developed system: The developed system was tested to be an effective machine in the deep-litter poultry farming system. The ability of the system to operate with little or no human involvement makes it even more effective. Its sensing ability also makes it suitable on a large farm where it will effectively and efficiently feed a large number of birds within a very short period of time. This was achieved with module by module testing of both hardware and software subsystems.

The hardware testing involved testing of both discrete and active components of individual unit to conform to expected performance level). The sensors in the sensing unit was tested to verify their degree of sensitivity). The motor control circuit through the microcontroller was tested and verified to provide appropriate bias voltage to switch both BC547 transistor and $12 \mathrm{~V}$ relay connected to individual dc motor to different locomotive directions. Also, the software was tested and debugged before the working program was finally achieved.

However, different mechanical motion transmission systems were combined together to ensure the mobility of the system; therefore appropriate maintenance culture should be adopted which involves, lubricating these motion transmission systems at regular intervals, ensuring that the dc motors and the battery are in proper working condition.

\section{CONCLUSION}

This study has successfully presented a functional and low complexity mobile intelligent feed dispenser for deep litter poultry farmers. The developed system has the 
ability to sense, detect and avoid obstruction; dispense solid feeds and thus could be applied to larger farms and cater for a higher number of birds. This machine can do most of what the poultry attendants are required to do. Large number of the machine can be produced commercially after necessary fine-tuning and simulation to ensure greater income and high return of investment from poultry farming.

\section{RECOMMENDATIONS}

Every good engineering design has limitations; the limitation of this design could be improved upon in future by considering the following salient recommendations:

- Addition of a charger with the dispenser to enable the dispenser to operate for a longer period of time

- The dispenser should be improved to cater for liquid feeds like water

- The machine should be improved to enhance features that allows for grinding of solid feeds in order to feed young poultry birds

\section{REFERENCES}

Adedinsewo, O., 2004. Design and construction of a computer controlled poultry feed dispenser and temperature regulator. B. Tech. Thesis, Department of Computer Science and Engineering, Ladoke Akintola University of Technology, Ogbomoso, Nigeria.
Arulogun, O.T., O.M. Olaniyi and A.A. Ipadeola, 2008. Development of a computer-controlled security gate system. Pac. J. Sci. Technol., 9: 371-376.

Nierenberg, D., 2006. State of the World 2006. World Watch Inst., Washington, DC., pp: 26.

Odunsi, A.A., 2009. A Practical Approach to Animal Production and Health. Oluseyi Press, Ibadan.

Oke, A.O., O.M. Olaniyi, O.T. Arulogun and O.M. Olaniyan, 2009. Development of a microcontroller-controlled security door system. Pac. J. Sci. Technol., 10: 398-403.

Oluyemi, J.A. and F.A. Robelt, 1986. Poultry Production in Warm Wet Climate. Macmillan, Nigeria.

Omosebi, B.I., 2006. Development of a self propelled poultry feed dispenser with feed level detector. B. Tech. Thesis, Department of Computer Science and Engineering, Ladoke Akintola University of Technology, Ogbomoso, Nigeria.

Sainsbury, D., 2000. Poultry Health and Management (Chicken, Turkeys, Ducks, Geese and Quail). Blackwell Publishing, Great Britain.

Shoewu, O. and O.T. Baruwa, 2006. Design of a microprocessor based automatic gate. Pac. J. Sci. Technol., 7: 31-44.

Susan, M. and P. Anne, 1988. Tropical and Subtropical Foods. MacMillian, London.

Theraja, B.L. and A.K. Theraja, 2002. A Textbook of Electrical Technology. S. Chand, New Delhi. 